\title{
Antelias kirja Kaija ja Heikki Sirenin arkkitehtuurista
}

Riitta Nikula

Juhana Lahti \& Frans Autio, toim. Kaikki ja ei mitään. Arkkitehdit Kaija + Heikki Siren (Helsinki: Suomen arkkitehtuurimuseo, 2020), 159 sivua. Kirjoittajat Juhana Lahti, Elina Standertskjöld, Osmo Lappo, Frans Autio, Susanna Aaltonen ja Kirsi Siren.

Sotien jälkeisen Suomen ankarassa arjessa kasvoi arkkitehteja, jotka kehittivät innovatiivisesti uutta arkkitehtuuria yksityisiin ja julkisiin tehtäviin. Heistä Kaija (1920-2001) ja Heikki (1918-2013) Siren nousivat huomion kohteeksi 1950-luvun alusta lähtien. He perustivat yhteisen toimistonsa 1940-luvun lopulla ja jatkoivat yhteistyötä 1980-luvulle asti. Sen jälkeen toimiston työtä on jatkanut heidän poikansa Jukka. Arkkitehtisukupolvien ketju on poikkeuksellinen, kun muistetaan, että Heikin isä oli J.S. Sirén, Eduskuntata-

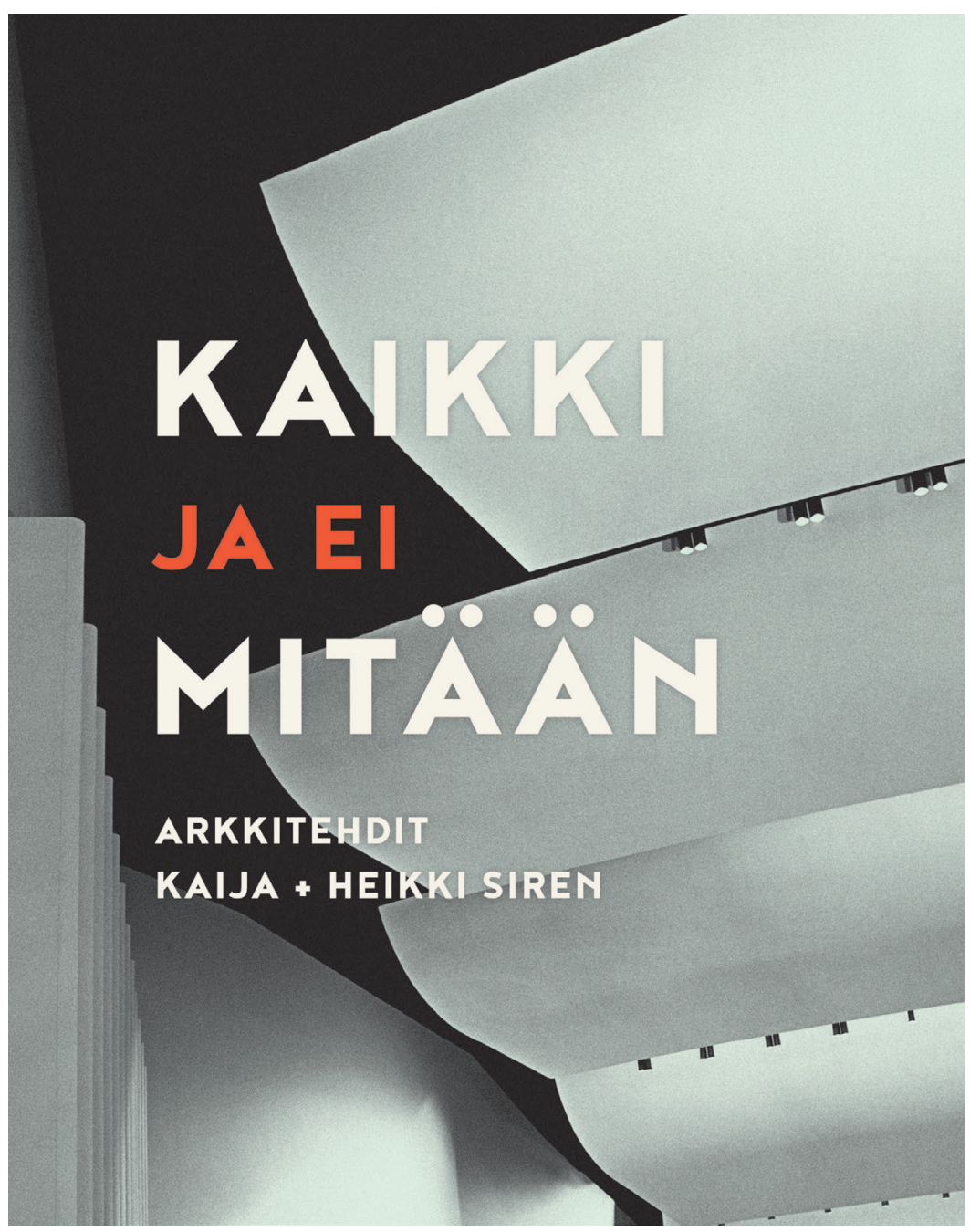

\section{Ninjet-turvinl:}

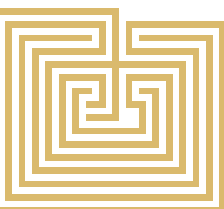


Ion arkkitehti ja Teknillisen korkeakoulun nykyaikaisen arkkitehtuurin professori.

Sirenien työstä on pitkään kaivattu tutkimukseen perustuvaa kirjaa. Otavan 1976 julkaisema suurteos on kaunis kuvakirja, joka herättää mielihyvää ja mielenkiintoa, mutta ei vastaa herättämiinsä kysymyksiin.

Arkkitehtuurimuseo ja Espoon Kaupunginmuseo KAMU yhdistivät voimansa Siren-tutkimuksessa. Arkkitehtuurimuseo julkaisi tukevan kirjan Kaikki ja ei mitään. Arkkitehdit Kaija + Heikki Siren ja KAMU teki WG-keskukseen Elina Standertskjöldin kuratoiman näyttelyn, joka valitettavasti jäi koronakaranteenin jalkoihin. Onneksi tuore kirja onnistui erinomaisesti ja siinä on keskeisiin teemoihin keskittyvät tutkielmat, hyvät kuvat ja tarpeelliset luettelot.

Kirjan toimittajat, Juhana Lahti ja Frans Autio, saivat aikaan opuksen, jossa tuore arkkitehtuurianalyysi liittyy suunnittelijoiden elämänkulkuun. Monipuolinen kokonaisuus tarjoaa paljon kaikille.

Juhana Lahden johdanto avaa Sirenien minimalismiin pyrkinyttä suunnittelutyötä "redusoiden jalostettuna arkkitehtuurina". Käsitteiden täsmällinen selittäminen palkitsee lukijaa. Heikki Sirenin puheenparteen ei teoretisointi kuulunut.

Muistan ikuisesti, miten Heikki 1968 selitti Hakaniemen ympyrätalon ratkaisun löytymistä talon valmistuttua. Ryhmä seisoi talon juurella. Arkkitehti kuvaili vauhdikkaasti ongelmia, joita vilkkaan liikenteen jär- jestäminen vanhan asemakaavan kulmikkaisiin ratkaisuihin olisi aiheuttanut. Hän viittaili Arenan talon pyöreään kulmaan ja Hämeentieltä Siltasaarenkadulle valuvaan autojen jonoon ja kiepautti sitten kädellään ilmaan ympyrän. "Sitten me keksittiin, että ympyränmuotoinen talo ratkaisee ympäristön ja liikenteen ongelmat".

Syvempien ulottuvuuksien löytäminen ja selittäminen jäi jälkipolville. Siinä uusi kirja onnistuu erinomaisesti. Lahti jatkaa redusoinnista arkkitehtuurin klassisten peruskysymysten pariin ja sijoittaa Kaija ja Heikki Sirenin työn luontevasti J.S:n luomalle tukevalle perustalle. Tällaista selkeyttä ei tavoita, jos katse ja ajattelu ovat takertuneet tyylihistorian kaavoihin.

Lahti keskittää huomion Sirenien materiaalien tajuun ja rakenneratkaisujen kehittämiseen yhdessä insinöörien kanssa. Yhteistyö oli ydinasia kokeellisessa puuelementtirakentamisessa, jota Heikki kehitti kymmeniä vuosia Puutalo Oy:n kanssa.

Analysoidessaan Sirenien tilasommittelua Lahti korostaa vertikaalisten siirtymien taitavaa hallintaa. Tässä yhteydessä hän muistuttaa, että sisäänkäyntien ja porrasnousujen korostaminen kuului myös klassisen arkkitehtuurin keinoihin.

Asuntoarkkitehtuurin suunnittelijoina Sirenit nousivat eturiviin jo 1953 voittamalla Asuntoreformikilpailun arkkitehtonisen ja sosiaalisen sarjan ehdotuksellaan, jossa oli keskeistä rivitalojen kehittäminen. Sirenit osallistuivat ahkerasti kilpailuihin. Lahti laskee, että he 1956-61 saivat maininnan 17:ssä, joista voittoja oli 11. Aktiivisimpina aikoina toimistossa työskenteli jopa 30-40 henkeä.

Elina Standertskjöldin artikkeli jatkaa ja laventaa saumattomasti Lahden tekstiä. Sirenien toimiston projektit kasvavat ja julkinen sektori tarjoaa uusia haasteita. Maa tarvitsee kouluja, liikerakennuksia, hallintorakennuksia, kulttuurirakennuksia, teollisuusrakennuksia, urheilukeskuksia, kirkkoja ja kappeleita sekä asemakaavoja. Menestys kilpailuissa jatkuu ja johtaa valtaviin tehtäviin myös ulkomailla. Bagdadin monumentaalinen konferenssipalatsi ja Linzin uljas konserttitalo lienevät parhaiten tunnettuja. Suomen Saudi-Arabian lähetystö ja Pariisin esikaupungin ketjutaloalue tunnetaan huonommin.

Standertskjöld selvittää suuren tuotannon tasapainoisesti ottaen esille yleisempiä näkökohtia töissä ja ajassa luontevasti edeten. Näin hän välttää hallitusti luettelomaisuuden ongelman.

Kansainvälisistä vaikutteista kysyttäessä Sirenit nostivat 1981 haastattelussa kärkeen japanilaisen puurakennusperinteen, sotien jälkeisen brasilialaisen arkkitehtuurin ja Mies van der Rohen. Richard Neutran, jonka töihin Sirenien töitä on aiheesta verrattu, he olivat tavanneetkin ensimmäisellä Amerikan-matkallaan 1960. Kiinnostava, mutta ei yllättävä tieto on sekin, että toimistossa luettiin tarkimmin 1950-1960 luvuilla tanskalaisia arkkitehtuurilehtiä. 
Otaniemen teekkarikylän monivaiheisen suunnitteIun ja rakentamisen yhteydessä Standertskjöld nostaa selkeästi ja monipuolisesti esille rakennustekniikan. Materiaalien ja rakenteiden innovatiivinen käyttö ja kehittäminen pommituksen rauniolta kerätyistä tiilistä vaihtelevien muuraustapojen kautta paljaiden puukonstruktioiden rohkeaan nousuun julkisiin tiloihin on vahva tarina. Menestyksekäs yhteistyö insinöörien kanssa jatkui 1950-luvulta lähtien pitkälle.

Pientalojen elementtirakentamisessa Sirenit olivat pioneereja. Tapiolan Kontiontien rivitalojen puiset julkisivuelementit, kooltaan peräti 16 neliömetriä, Sirenit suunnittelivat yhdessä Puutalo Oy:n kanssa. Rivitalojen elementtien kehittäminen johti yhä suurempien tilaelementtien valmistamiseen tehtaalla.

Kansallisteatterin pieni näyttämö oli 1950-luvulla maan ensimmäinen moderni teatterirakennus. Sirenit ratkaisivat sen tuomalla Onni Tarjanteen teatterilinnan taakse ja Eliel Saarisen päärautatieaseman naapuriksi askeettisen modernin kuution. Sen tiukka muoto- ja materiaaliratkaisu oli niin vahva kontrasti vanhalle, että Pietisen usein julkaistu kuva on usein, kuten tässäkin kirjassa (42) retusoitu ja rajattu niin, että vanhan päänäyttämön lavastetorni ei näy kuvassa. Alkuperäisessä kuvassa torni näkyy ylhäällä ja myös heijastuksena vesialtaassa. Sellainenkin kuva on julkaistu, jossa torni on retusoitu Sirenien teatterin yläpuolelta, mutta näkyy komeasti altaan vesipeilissä. Ainoa korjausehdotukse- ni tämän kirjan seuraavaan painokseen onkin: ottakaa kuva, jossa torni on retusoitu talon yltä, mutta heijastuu veteen. Kuvatekstissä voisi avata keskustelua historiallisen kerrostuneisuuden arvostuksesta rakennetussa ympäristössä.

Kirkot, koulut ja kansainväliset työt jatkavat kooltaan kasvavien töiden ketjua. Selkeät perusmuodot ja taitavat valaistusratkaisut löytyvät. Turhaa ei tarvita. Ote pitää.

Esikoistyttären, Kirsi Sirenin artikkeli "Kotkan ruusu ja pikkusireeni" on teatteriammattilaisen riemastuttava kuvaus perhe-elämästä. Vanhempiensa ja isovanhempiensa kuvat Kirsi maalaa niin reippailla väreillä, että lukija näkee mielessään suurmiehet ja mahtinaiset vauhdissa elämän suurella näyttämöllä. En ole ennen lukenut yhtä rehellisesti rakastavaa ja avoimesti nauravaa kuvausta vanhemmista sukupolvista ja onnellisesta lapsuudesta. Kiitos Kirsi!

Osmo Lapon artikkeli "Heikin kyydissä" tuo kirjaan 10 vuotta nuoremman kollegan kokemukset. Lappo oli opiskelijana voittanut Teekkarikylän kolmosvaiheen sisustuskilpailun ja tuli Sirenien toimistoon nuorimpana neljästä työntekijästä (1952-1953). Lappo kertoo kiinnostavasti kokemuksistaan monissa hankkeissa ja muistelee, että "arkkitehtuurifilosofisia keskusteluja ei muistini mukaan toimistossa käyty. Työssä oli vahva tekemisen meininki."

Susanna Aaltonen hakee sisätiloihin keskittyvän artikkelinsa alussa Kaija Sirenin panosta yhteisessä toimistossa. Laaja-alainen kulttuuriharrastus ja visuaa- lisen kulttuurin arkistenkin ilmiöiden arvostaminen oli Kaijan vahvuutta. Vaikka hänen osuuttaan yhteisestä suunnittelusta on hankala erottaa, värien valintaa hän ilmeisesti johti. Ainakin Andreas Kornerupin ja Johan Henrik Wancherin Värien kirjasta (1961) Aaltonen löytää Kaijan merkintöjä.

Sirenien vertaaminen Lilly Reichin ja Mies van der Rohen kriittisesti tutkittuun yhteistyöhön on perusteltua. Vaikka työnjako jää hämäräksi ja sitä on hankala tarkkaan määritellä, analyysi selventää suunnitteluprosessia. Aaltonen löytää myös toimiston piirustuksista kolmenlaisia leimoja: "Heikki Siren, arkkitehti SAFA", "Arkkitehtuuritoimisto Kaija ja Heikki Siren" ja "Sisustusarkkitehtuuritoimisto Siren". Hän päätyy nimeämään Heikin orkesterin johtajaksi ja kapellimestariksi, Kaijan orkesterin intendentiksi.

Avustajien joukossa oli myös sisustusarkkitehteja, jotka olivat vasta etsimässä paikkaansa suunnittelutoimistoissa. Lars Gestranius oli Sirenien palkkalistoilla 1956-1968 ja osallistui 138 kohteen suunnitteluun. Monet sisustusarkkitehdit aloittivat toimistossa uran, joka jatkui oman toimiston yhteistyönä Sirenien kanssa.

Sirenien tuotannosta Aaltonen on valinnut sisätilojen keskitetyn tarkastelun kohteeksi edustavan joukon toisistaan poikkeavia keskeisiä töitä: oman koti- ja toimistotalon, Otsonpesän rivitalon, Otaniemen kappelin, Kansallisteatterin pienen näyttämön, Ympyrätalon ja Suomalaisen Yhteiskoulun tilat. 
Kaikissa asuintaloissa Sirenit sijoittivat yksityiset tilat yläkertaan ja yhteisen oleskelun ja aputilat alakertaan. Perheasunnot suunniteltiin lapsiperheiden arkeen. Aravarivitaloista viiden tilavan asunnon Otsonpesän kalliiseen eleganssiin perusratkaisu oli periaatteessa sama.

Otsonpesästä asuntojen väljä mitoitus ja pintojen korkeatasoiset materiaalit tekivät erityisen loistokohteen. Lars Gestranius suunnitteli huoneisiin myös uniikkeja sisustuselementtejä pukeutumistiloista työhuoneisiin. Julkaisukuvien televisio-, radio- ja levysoitinkaappi saattoi aikanaan herättää vähävaraisemmissakin halua olohuoneen modernisointiin.

Otaniemen kappelin analyysi keskittyy kalusteiden yksityiskohtiin ja yhteenkuuluvuuteen, joka viimeisteli interiöörin harmonisen askeesin. Tässä kohteessa kalusteet suunnitteli Heikki Siren. Kappeli on toimiston ainoa työ, jonka Heikki ja Kaija tekivät lähes kokonaan kaksin.

Maailma ja arkkitehtuuri muuttuivat 12 vuodessa Otaniemen kappelin valmistumisesta 1956 KOP:n Ympyrätalon vihkiäisiin 1968 niin perin pohjin, että ulkopuolisen lienee mahdoton uskoa niitä samojen arkkitehtien töiksi. Murros toi arkkitehdeille uudet vaatimukset - ja mahdollisuudet. Ympyrätalon alkuperäinen eleganssi kiiltää ja loistaa kuvissa kylmästi. Aaltonen lainaa osuvasti pankin mainosvideon tekstiä selittämään ajan henkeä.

Ympyrätalon tieltä purettiin aimo pala vanhaa kau- punkia, monta Heikki Kaartisen suunnittelemaa asuintaloa. Nyt uusi talo on kokenut jo monta muutos- ja korjauskierrosta. Pelottavan elegantti pyöreä pankkisali on purettu. Ympyrän ytimessä on nyt sekalaisia kauppaliikkeitä ja autopankki hakee uutta käyttöään.

Koulujen suunnittelussa Sirenit osuivat onnellisesti 1970-luvun koulu-uudistuksen toteuttajiksi. Suomalainen Yhteiskoulu nimettiin kokeilukouluksi. Sirenit suunnittelivat uudistukselle kaikesta vanhasta poikkeavat tilat ja hahmon, joka mursi maan kouluarkkitehtuurin vanhat konventiot.

Kirjan riemastuttavin yllätys on Frans Aution artikkeli "Ajattoman puuarkkitehtuuriperinteen äärellä Suomessa ja Japanissa". Sirenien omat puheet ja monen arkkitehtuurilehdenkin artikkelit ovat toki vuosikymmeniä rinnastaneet Sirenien arkkitehtuuria Japanin perinteisiin, erityisesti perheen Lingonsön saarelle rakentamia vapaa-ajan rakennuksia, mutta tutkimusta aiheesta en ole nähnyt. Tekstit ovat jääneet tunnelmoinniksi ja kuvien silmämääräiseksi vertailuksi. Harva on ylittänyt korkean kieli- ja kulttuurimuurin.

Japanin arkkitehtuuriin perehtyneenä ja maan kieltä taitavana Frans Autio tutkii nyt ensimmäisenä Sirenien ja Japanin suhdetta monipuolisesti ja selvittää kriittisesti erilaisia tulkintamahdollisuuksia. Analyysi keskittyy kahteen Sirenien Japaniin suunnittelemaan golfkeskukseen, joita hän pitää todennäköisesti ensimmäisinä suomalaisarkkitehtien Japaniin rakennettuina kohteina. Suomen töistä hän keskittyy Otaniemen kappeliin ja Lingonsön lomasaaren rakennuksiin.

Aution huomiot osuvat. Heikki Sireniltä alkuun lainattu repliikki Lingonsön kappelista hillitsee lukijankin mielikuvituksen holtitonta lentoa. "Siitähän on suomalaiset sanonu et se on niin japanilaisen näkönen ja japanilaiset sano et sehän on ihan suomalaisen näkönen."

Aution teksti japanilaisuuden myytistä on tiivis johdatus aiheeseen. Hän löytää Arata Isozakin esseistä kiinnostavasti tukea tavalla, joka saa ainakin tämän kirjoittajan kiinnostumaan japanilaisen mestarin ajattelusta, vaikka hänen postmodernistinen rakennustaiteensa ei ole herättänyt erityistä mielenkiintoa. Isozakia seuraillen Autio osoittaa terävästi, miten kapeasti valikoiden japanilainen arkkitehtuuri on eurooppalaisia kiinnostanut.

Otaniemen kappelin metsään aukeava tila johtaa Aution analyysin Japanin uskontojen synkretismiin ja siitä edelleen suomalaiseen rahvaanuskontoon, jonka luonnetta ja tapoja akateemikko Anna-Leena Siikala on selvittänyt. Aution laaja-alaiset lähteet johtavat hyvin perusteltuihin syviin ajatuksiin. Hänen analyysinsa Otaniemen kappelin kaikkia koskettavasta pyhästä tilasta on ihailtava! Pateettisuutta välttääkseni lainaan tueksi Heikki Sireniltä samaan yhteyteen saatua haastattelusitaattia: "Siel on ollut buddhat ja shintot ja venäläiset ja kaikki niinku hyväksyy sen."

Kesäparatiisinsa Sirenit rakensivat Lingonsön saarelle 1966-1969. Matalat asuinrakennukset asettuvat 
terasseineen kaartuvana ketjuna kalliomaisemaan, kappeliksi kutsuttu rakennus sijoitettiin erikseen katsomaan avomerelle. Japanilaisuudeksi Autio toteaa mutkattoman koruttomuuden ja sisä- ja ulkotilojen yhdistämisen laajojen terassitasojen avulla. Hirsirakenteet ovat käsittelemättömiä, tehtaalla esivalmistettuja.

Japanissa 1965 julkaistu The Kindai Kechiku -lehti omisti yhden numeron Sirenien arkkitehtuurille. Kiinnostus heräsi siis jo ennen kesäparatiisin rakentamista. Sirenien koruton arkkitehtuuri puhutteli japanilaisia syvästi, ja he saivat 1970-luvun alussa ensimmäisen kutsun Seibu -yhtiöltä. Vuonna 1974 valmistunut golfkeskuksen ravintola Karuizavassa sai nimen Utsjoki. Sama yhtiö tilasi Sirenit suunnittelemaan vielä Onumaan golfkeskuksen, joka valmistui 1976. Golfkeskukset on sittemmin purettu, ja Sirenien arkkitehtuuria edustaa Japanissa enää kolme lomakylää, joissa on yhteensä satoja vuokrattavia hirsimökkejä

Kaija ja Heikki Siren ovat nyt saaneet arvoisensa paikan suomalaisten arkkitehtuurikirjojen joukossa, joka on karttunut ilahduttavasti kuluneen vuoden aikana. Rohkenen liittää lopuksi sen vertailevaan luetteloon, koska olen huomannut monien arkkitehtuurikirjojen välttävän laajemman julkisuuden.

Riitta Nikula on Helsingin yliopiston taidehistorian professori emerita.

\section{Kirjasuosituksia Riitta Nikulalta:}

* Juhana Lahti \& Frans Autio, toim. Kaikki ja ei mitään. Arkkitehdit Kaija + Heikki Siren (Helsinki: Suomen arkkitehtuurimuseo, 2020 on kaivattu kirja, joka onnistuu maltillisessa koossa (158 s.) tavoittamaan paljon. Se on huolellisesti dokumentoitu viiden tutkijan tuoreen artikkelin kooste, ilo asiantuntijoille ja samalla kirja kaikille arkkitehtuurista kiinnostuneille. Tutkijat tahtovat nykyään välttää suomenkielistä julkaisemista, koska englanniksi saa enemmän arvostuspisteitä. Toivon tietysti, että kirja ilmestyy vielä englanniksi, koska kansainvälistäkin kiinnostusta on.

* Netta Böök \& Kari Immonen, toim. \& Aino Niskanen, arkkitehtuurin historian asiantuntijatoim. sekä Laura Berger, kuvatoim.: Uno Ullberg. Viipurin arkkitehti (Uno Ullberg -seura \& Arkkitehtuurimuseo, 2020). Teos on peräti 23 suomalaisen ja neljän venäläisen tutkijan yhteinen ponnistus mestarista, joka on unohtunut kahdessa maassa. Monumentaalinen kirja on niin suuri, että sitä voi lähestyä ensin näyttelynä ja sitten syventyä asiantunteviin artikkeleihin. Vaativa ratkaisu on perusteltu siksikin, että Ullbergin päätöiden kunnostaminen on Viipurissa ajankohtaista. Ks. Susanna Aaltosen arvio tässä julkaisussa.

* Teppo Jokinen, Arvorakennusten arkkitehti. Gustaf Nyström suunnittelijana ja opettajana Helsinki: PARVS, 2020) on odotettu elämäkerta.

* Esa Laaksonen, Else Aropaltio, arjen arkkitehti (Helsinki: Pen \& Paper, 2020) on kelpo kirja ahkerasta asuntosuunnittelijasta, joka sitoo Aropaltion paikkaan ja aikaan. Teoksessa on hyvät kuvat ja plaanit ja se nostaa näkyville arkiarkkitehtuurin miljöön ja mestarin, jota ei ennen juuri tunnettu Lauttasaaren ulkopuolella.

* Mikko Laaksonen, Betoni ja modernismi, Arkkitehti Pekka Pitkänen 1927-2018 (Berlin: DOM publishers, 1921). Ansiokas työluettelon täydentäminen reippaalla journalistisella otteella. Enemmän opas kuin opetus. Hyvä johdanto syventyvään tutkimukseen ansiokkaasta elämäntyöstä. 